\title{
Relationship between protein O-linked glycosylation and insulin-stimulated glucose transport in rat skeletal muscle following calorie restriction or exposure to $\mathrm{O}$-(2-acetamido- 2-deoxy-D-glucopyranosylidene)amino- $\mathbf{N}$-phenylcarbamate
}

\author{
E. B. Arias and G. D. Cartee \\ Division of Kinesiology, University of Michigan, Ann Arbor, MI, USA
}

Received 19 April 2004 accepted 21 October 2004 Correspondence: E. B. Arias, Division of Kinesiology, University of Michigan, 40I Washtenaw Avenue, Ann Arbor, Ml 48109, USA.

\begin{abstract}
Aims and Background: Protein $O$-linked glycosylation is regulated invivo by the concentration of hexosamine substrates. Calorie restriction $160 \%$ of ad libitum intake) for 20 days causes decreased UDP- $N$-acetylhexosamine levels and increased insulin-mediated glucose transport in rat skeletal muscle. Conversely, prolonged incubation (19 h) of muscle with O-(2-acetamido-2-deoxyD-glucopyranosylidene)amino- $N$-phenyl-carbamate (PUGNAc; an inhibitor of $N$-acetyl- $\beta$-D-glucosaminidase) is characterized by increased $O$-linked glycosylation and insulin resistance. We aimed to determine the calorie restriction effect on $O$-linked glycosylation and characterize the temporal relationship between PUGNAc-induced O-linked glycosylation and insulin resistance.

Hypothesis: A calorie restriction protocol characterized by decreased muscle hexosamine levels will result in a global reduction in O-linked glycosylated proteins in muscle, and PUGNAc-induced insulin resistance will coincide with increased $O$-linked glycosylation.

Methods: Plantaris muscle and liver from rats (ad libitum or calorie restricted) were analysed for $O$-linked glycosylation using two antibodies against different $\mathrm{O}$-linked $\mathrm{N}$-acetylglucosamine epitopes. Also, rat epitrochlearis muscles were incubated for $8.5 \mathrm{~h} \pm 100 \mu \mathrm{M}$ PUGNAc prior to measurement of $\left[{ }^{3} \mathrm{H}\right]-3-\mathrm{O}$-methylglucose transport and $\mathrm{O}$-linked glycosylation.

Results: Calorie restriction did not alter protein O-linked glycosylated levels in muscle or liver. Incubation with PUGNAc for $8.5 \mathrm{~h}$ resulted in increased in O-linked glycosylation but unaltered basal or insulin-stimulated glucose transport.

Conclusions: The delay between $O$-linked glycosylation and insulin resistance in muscle incubated with PUGNAc suggests an indirect, relatively slow mechanism for insulin resistance. The effect of calorie restriction on insulin action in muscle is unlikely to be the direct result of a global change in protein $\mathrm{O}$-linked glycosylation.

Keywords diet restriction, food restriction, hexosamine, insulin resistance, O-GlcNAcylation, PUGNAc.
\end{abstract}

The hexosamine biosynthetic pathway (HBP) and posttranslational modification of proteins via $\mathrm{O}$-linkage of a single $\mathrm{N}$-acetylglucosamine to serine and threonine residues (O-GlcNAcylation) have been likened to a nutrient sensing mechanism and suggested to modulate glucose metabolism (Wells et al. 2003). It has been 
estimated that a small fraction of the glucose $(3-5 \%)$ that enters cells is directed through the HBP (Marshall et al. 1991). Fructose-6-phosphate and glutamine are converted to glucosamine-6-phosphate by glutamine/ fructose-6-phosphate amidotransferase (GFAT), the first- and rate-limiting step in the HBP. UDP- $N$ acetylglucosamine (UDP-GlcNAc), an endproduct of the HBP, serves as the substrate for $\mathrm{O}$-glucosamine transferase (OGT) in the O-linked glycosylation of proteins on specific serine and threonine residues (Hart 1997). O-GlcNAcase is a nucleocytoplasmic enzyme and the neutral glycosidase that cleaves O-GlcNAc from the protein, a process that is analogous to the dephosphorylation function of a phosphatase. Thus, $\mathrm{O}$-GlcNAcylation is a dynamic process of transfer and removal of O-GlcNAc and has been detected in normal and abnormal conditions.

Marshall et al. (1991) first described the relationship between the HBP and insulin-stimulated glucose uptake in cultured adipocytes. Subsequently, a number of conditions which have increased flux through the HBP, e.g. prolonged hyperglycemia (Rossetti et al. 1990), increasing plasma levels of glucosamine (YkiJärvinen et al. 1998), and transgenic mice overexpressing GFAT (Hebert et al. 1996), have been demonstrated to also be characterized by insulin resistance. Several studies have provided evidence that alterations in protein $\mathrm{O}$-GlycNAcylation can influence insulin action. Vosseller et al. (2002) reported that prolonged (19 h) incubation of 3T3-L1 adipocytes in O-(2-acetamido-2deoxy-D-glucopyranosylidene)amino- $N$-phenyl-carbamate (PUGNAc), a potent inhibitor of $N$-acetyl- $\beta$-D-glucosaminidase (O-GlcNAcase), induced extensive O-GlcNAcylation of proteins as well as insulin resistance for glucose uptake. Recently, we reported similar findings in rat epitrochlearis muscle: prolonged $(19 \mathrm{~h})$ incubation in PUGNAc elicited increased O-GlcNAcylation of multiple proteins identified using an antibody against $\beta$-O-linked $\mathrm{N}$-acetylglucosamine. Furthermore, PUGNAc also induced a decrease in glucose transport with a physiologic insulin concentration (Arias et al. 2004).

In contrast to interventions which lead to insulin resistance, calorie restriction (CR; consuming $60 \%$ of ad libitum, $\mathrm{AL}$, intake) by rats or mice can increase insulin-stimulated glucose transport by skeletal muscle, and this effect can occur with only 20 days of CR (Cartee \& Dean 1994, Dean \& Cartee 1996, Dean et al. 1998, Gazdag et al. 1998, 2000, Davidson et al. 2002, McCurdy et al. 2003). It would be important to identify the molecular processes that trigger the CR-induced increase in insulin sensitivity. Consistent with the apparent inverse relationship between HBP flux and insulin sensitivity, the CR-induced increase in insulin-stimulated glucose transport is accompanied by a reduction in skeletal muscle levels of
UDP- $\mathrm{N}$-acetylhexosamines (acetylglucosamine and acetylgalactosamine) (Gazdag et al. 2000).

O-GlcNAcylation appears to be predominantly regulated by the cellular concentrations of UDPGlcNAc (Kreppel \& Hart 1999). In light of the CRinduced decline in UDP-GlcNAc levels in skeletal muscle (Gazdag et al. 2000), in this study, our principal aim was to assess possible differences between calorie restricted and ad libitum rats in protein O-GlcNAcylation of skeletal muscle. In addition, to gain more insights into the link between protein $\mathrm{O}$-GlcNAcylation and insulin action, we performed further research using PUGNAc with isolated skeletal muscle. Previous studies found that $19 \mathrm{~h}$ of incubation in PUGNAc induced insulin resistance in 3T3-L1 adipocytes (Vosseller et al. 2002) and skeletal muscle (Arias et al. 2004). It seemed valuable to further examine the temporal relationship between PUGNAc's effects on protein O-GlcNAcylation and insulin-stimulated glucose transport. Accordingly, we assessed the effects of a shorter duration $(8.5 \mathrm{~h})$ of PUGNAc exposure on incubated rat skeletal muscle prior to measuring protein O-GlcNAcylation status and glucose transport.

\section{Methods}

\section{Materials}

Unless otherwise noted, all chemicals were purchased from Sigma Chemical (St Louis, MO, USA) or Fisher Scientific (Hanover Park, IL, USA). Teklad Rodent Diet no. 8604 was purchased from Harlan Teklad (Madison, WI, USA). Dulbecco's Modified Eagle's medium (DMEM; catalogue no. 31600) was purchased from GIBCO Invitrogen (Grand Island, NY, USA). O-(2-acetamido-2-deoxy-D-glucopyranosylidene)amino$\mathrm{N}$-phenyl-carbamate (PUGNAc) was purchased from CarboGen Labs (Aarau, Switzerland). Human recombinant insulin (HumulinR) was purchased from Eli Lilly (Indianapolis, IN, USA). [ $\left.{ }^{3} \mathrm{H}\right]-3-\mathrm{O}$-methylglucose and $\left[{ }^{14} \mathrm{C}\right]$-mannitol were purchased from NEN (Downers Grove, IL, USA). Reagents and apparatus for SDS-PAGE and immunoblotting were obtained from Bio-Rad (Richmond, CA, USA). Anti- $\beta$-O-linked $\mathrm{N}$-acetylglucosamine (CTD110.6 clone; catalogue no. MMS-248R) antibody was purchased from Covance (Princeton, NJ, USA). Anti-O-linked $\mathrm{N}$-acetylglucosamine (RL2 clone; catalogue no. MA1-072) was purchased from Affinity Bioreagents (Denver, CO, USA). Reagents for the bicinchoninic acid (BCA) protein assay were purchased from Pierce Biotechnology (Rockford, IL, USA). Enhanced chemiluminescence (ECL) kits were purchased from Amersham Pharmacia Biotechnology (Piscataway, NJ, USA). 


\section{Animal treatment}

All animal procedures were approved by the Animal Care and Use Committee of the University of Wisconsin-Madison. We performed two experiments: for Experiment 1, 4 month old, male Fischer $344 \times$ Brown Norway, F1 generation (F344BNF1/Nia) rats were obtained from the National Institute on Aging from Harlan Sprague Dawley (Indianapolis, IN, USA). For these animals, a four-step diet protocol was used (Davidson et al. 2002). Step 1: Upon arrival at the animal facility, the rats were provided with chow and water ad libitum for an 1-week acclimatization period. Step 2: Subsequently, individual baseline food intake was determined by allowing rats unlimited access to food for 1 week and measuring food intake corrected for spillage. Step 3: Animals were then familiarized to a meal-feeding protocol for another week. The mealfeeding protocol consisted of providing rat chow in three 1.5 -h periods over the course of each day. Step 4: Following the familiarization period, the ad libitum (AL) rats were given $100 \%$ of their individual baseline intake for a period of 20 days, while the CR rats received $60 \%$ of their individual intake for 20 days as determined during the baseline period. Both groups received the same per cent allotment accordingly (35\% at $06: 00 \mathrm{~h}, 25 \%$ at $15: 00 \mathrm{~h}$, and $40 \%$ at $20: 00 \mathrm{~h}$ ).

For experiment 1, animals received their 06:00 h meal on the experimental day, were transported from the animal facility to the laboratory at 10:00 $\mathrm{h}$ and were anaesthetized with an intraperitoneal injection of sodium pentobarbital $\left[5 \mathrm{mg}(100 \mathrm{~g})^{-1}\right.$ body $\left.\mathrm{wt}\right]$ between $12: 00 \mathrm{~h}$ and 14:00 h. Upon loss of pedal reflexes, plantaris muscles (fibre type composition: 15, 31 , and $54 \%$, for type I, type IIa, and type IIb, respectively) (Holloszy et al. 1991) and liver were quickly excised, freeze-clamped and stored at $-80{ }^{\circ} \mathrm{C}$ until further processing.

Experiment 2 was performed to assess the effects of in vitro incubation of skeletal muscle with $\mathrm{O}$-(2-acetamido-2-deoxy-D-glucopyranosylidene)amino- $N$-phenylcarbamate (PUGNAc), an inhibitor of the enzyme that catalyses removal of O-GlcNAc modifications from proteins. Male Wistar rats (1.5 month old) were obtained from Harlan (Indianapolis, IN, USA) and provided with Purina rat chow and water ad libitum. Upon arrival at the animal facility, the animals were acclimated to their surroundings for 2-3 days and fasted at 18:00 $\mathrm{h}$ on the night prior to each experiment.

For experiment 2, on the day of muscle dissections between 12:00 $\mathrm{h}$ and 14:00 $\mathrm{h}$, the animals were anaesthetized with an intraperitoneal injection of sodium pentobarbital [5 $\mathrm{mg}(100 \mathrm{~g})^{-1}$ body $\mathrm{wt}$ ]. Upon loss of pedal reflexes, epitrochlearis muscles (fibre type composition: 8,17 , and $75 \%$ for type I, type IIa, and type
IIb, respectively) (Wallberg-Henriksson 1987) were quickly excised and transferred into the tissue incubation media.

\section{Muscle incubation and glucose transport}

The protocol used for epitrochlearis incubation is similar to those previously described (Arias et al. 2004), but modified for $8.5 \mathrm{~h}$ rather than $19 \mathrm{~h}$ PUGNAc exposure. Briefly, following dissection, muscles were incubated for $8 \mathrm{~h}$ in flasks containing $1.5 \mathrm{~mL}$ low glucose $(5.5 \mathrm{mM})$ DMEM supplemented to contain $2.54 \mathrm{~mm} \mathrm{CaCl} 2$ and $25 \mathrm{~mm} \mathrm{NaHCO}_{3}$. Flasks were placed in a shaking water bath at $35{ }^{\circ} \mathrm{C}$ and continuously gassed with $95 \% \mathrm{O}_{2} / 5 \% \mathrm{CO}_{2}$ throughout the experiment. After $4 \mathrm{~h}$ incubation, the media was discarded and replaced with fresh DMEM supplemented as described above.

Following the $8 \mathrm{~h}$ incubation in supplemented DMEM, muscles were rinsed in Krebs-Henseleit buffer (KHB) supplemented with $0.1 \%$ BSA, $2 \mathrm{~mm}$ sodium pyruvate, and $5 \mathrm{~mm}$ mannitol for sequential $20 \mathrm{~min}$ and $10 \mathrm{~min}$ periods at $30^{\circ} \mathrm{C}$ to rinse away glucose and DMEM. During the rinse steps, the KHB was supplemented with $0,0.6$, or $12 \mathrm{~nm}$ insulin. Muscles treated with PUGNAc in the initial incubation steps continued to be exposed to $100 \mu \mathrm{M}$ PUGNAc during the subsequent rinse steps. Overall the PUGNAc-treated muscles were exposed to PUGNAc for a total duration of $8.5 \mathrm{~h}$ prior to incubation with 3-O-methyl-D-glucose.

Finally, muscles were incubated at $30{ }^{\circ} \mathrm{C}$ for $15 \mathrm{~min}$ in $1.5 \mathrm{~mL} \mathrm{KHB}$ containing $8 \mathrm{mM} \mathrm{3-O-methyl-D-glu-}$ cose $\left(\left[{ }^{3} \mathrm{H}\right]-3-\mathrm{MG} ; 0.5 \mathrm{mCi} \mathrm{mmol}^{-1}\right)$ and $2 \mathrm{~mm}$ mannitol $\left(\left[{ }^{14} \mathrm{C}\right]-0.2 \mathrm{mCi} \mathrm{mmol}^{-1}\right)$. Insulin concentrations remained the same as in the preceding rinse steps $(0$, 0.6 or $12 \mathrm{~nm}$ insulin). Muscles were then rapidly blotted, trimmed, clamp frozen with aluminium tongs cooled to the temperature of liquid $\mathrm{N}_{2}$, and stored at $-80{ }^{\circ} \mathrm{C}$ until further processing.

\section{Muscle preparation}

Frozen muscles were weighed, transferred to pre-chilled glass tissue grinding tubes (Kontes) and homogenized in ice-cold lysis buffer $\left(1 \mathrm{~mL}\right.$ muscle $\left.{ }^{-1}\right)$ containing $20 \mathrm{~mm}$ Tris-HCl, pH 7.4, $150 \mathrm{~mm} \mathrm{NaCl,} \mathrm{1 \%} \mathrm{NP-40} \mathrm{(v/v),}$ $2 \mathrm{~mm}$ EDTA, $2 \mathrm{~mm}$ EGTA, $1 \mathrm{~mm}$ dithiothreitol, $2.5 \mathrm{~mm}$ sodium pyrophosphate, $10 \mathrm{~mm}$ sodium fluoride, $2 \mathrm{~mm}$ sodium vanadate, $20 \mathrm{~mm} \beta$-glycerophosphate, $2 \mu \mathrm{m}$ PUGNAc, $1 \mu \mathrm{g} \mathrm{mL} L^{-1}$ leupeptin, $1 \mu \mathrm{g} \mathrm{mL}^{-1}$ pepstatin, $1 \mu \mathrm{g} \mathrm{mL}^{-1}$ aprotinin, and $2 \mathrm{~mm}$ phenylmethylsulfonyl fluoride. Homogenates were transferred to microfuge tubes, rotated for $1-2 \mathrm{~h}$ at $4{ }^{\circ} \mathrm{C}$ and then centrifuged at $12000 \times g$ for $15 \mathrm{~min}$ to remove insoluble material. Following homogenization, plantaris 
muscle and liver samples from the calorie restriction experiment were processed for Western blotting while epitrochlearis muscle samples from the PUGNAc-incubation experiment were used for determination of glucose transport as well as for Western blotting. Supernatants were transferred to fresh microfuge tubes and duplicate $200 \mu \mathrm{L}$ aliquots derived from epitrochlearis muscles were immediately used for scintillation counting. $\left[{ }^{3} \mathrm{H}\right]-3-M G$ uptake was determined as previously described (Davidson et al. 2002). Protein concentrations of all supernatants were determined by the BCA method (Smith et al. 1985).

\section{Immunoblotting}

Aliquots of supernatants were solubilized in SDS sample buffer, boiled for 3 min and subjected to $8-10 \%$ SDSPAGE. Resolved proteins were transferred to nitrocellulose paper overnight at a constant current of $150 \mathrm{~mA} /$ transfer apparatus in electrotransfer buffer $(20 \mathrm{~mm}$ Tris, $\mathrm{pH} 8.0,150 \mathrm{~mm}$ glycine, $0.025 \%$ SDS, $20 \%$ methanol). Nitrocellulose blots were blocked in TBSTHT $(0.3 \%$ Tween-20 in tris-buffered saline, $\mathrm{pH} 7.5)$ for $1 \mathrm{~h}$ at room temperature and transferred to fresh TBSTHT with either the CTD110.6 or RL2 anti-O-linked $\mathrm{N}$-acetylglucosamine antisera $(1: 1000)$ for $2 \mathrm{~h}$ at room temperature or overnight at $4{ }^{\circ} \mathrm{C}$. Blots were then washed and incubated in secondary antibody (goat antimouse IgM-HRP, CTD110.6; anti-mouse IgG-HRP, RL2; $1: 5000$ ) for $1 \mathrm{~h}$ at room temperature. Blots were washed of excess antibody, subjected to enhanced chemiluminescence, and immunoreactive protein was quantified by densitometry.

\section{Statistical analysis}

All data are expressed as mean \pm SE. Differences between groups (AL vs. CR) for the calorie restriction experiment were evaluated by $t$-test. Differences between groups for the PUGNAc experiment (PUGNAc vs. no PUGNAc) were evaluated by paired $t$-test. Statistics were performed using SigmaSTAT (SPSS, Chicago, IL, USA). $P \leq 0.05$ was considered statistically significant.

\section{Results}

O-linked glycosylation status of proteins from the plantaris muscle from experiment 1 (the calorie restriction study) was evaluated by Western blotting using two different monoclonal antibodies, CTD110.6 and RL2 (Fig. 1a). Multiple protein bands were detected by CTD110.6 and RL2 antibodies and subsequently were quantitated by densitometry (Fig. $1 \mathrm{~b}$ and c). No significant differences were found between $\mathrm{CR}$ and
AL in any of the detected protein bands using either antibody.

In addition, we assessed the O-GlcNAcylation status of the liver of experiment 1 ( $\mathrm{CR}$ and $\mathrm{AL}$ ) using the CTD110.6 antibody (Fig. 2a). Multiple protein bands were identified but no differences in O-GlcNAcylation were observed between the CR and AL groups (Fig. 2b).

For experiment 2, incubation of epitrochlearis muscles with $100 \mu \mathrm{M}$ PUGNAc for $8.5 \mathrm{~h}$ resulted in multiple protein bands demonstrating significantly increased immunoreactivity against the CTD110.6 antibody compared with paired muscles incubated without PUGNAc (Fig. 3a and b). As expected, glucose transport increased with increasing insulin concentrations. However, incubation with PUGNAc for $8.5 \mathrm{~h}$ did not affect glucose transport with any insulin concentration (Fig. 4).

\section{Discussion}

The most important findings from this study were, (1) CR did not cause a detectable difference between CR and $\mathrm{AL}$ rats for protein O-GlcNAcylation of insulinresponsive tissues, skeletal muscle and liver; and (2) PUGNAc-induced O-GlcNAcylation of skeletal muscle proteins preceded the development of insulin resistance.

Increased skeletal muscle insulin sensitivity is a hallmark of a moderate reduction in calorie consumption, having been documented in vivo with the euglycemic-hyperinsulinemic clamp of rats (Reaven et al. 1983), in perfused rat hindlimb (Ivy et al. 1991), and in isolated muscle preparations from rats and mice (Dean et al. 1998, Gazdag et al. 1999, Dean \& Cartee 2000, McCurdy et al. 2003). The effect is found rapidly, after only 20 days, in skeletal muscles of various fibre type composition, including the predominantly type I soleus (Gazdag et al. 1999), predominantly type II-a flexor digitorum brevis (Gazdag et al. 1998), and predominantly type II-b epitrochlearis (Dean et al. 1998, Gazdag et al. 1999, Dean \& Cartee 2000, McCurdy et al. 2003). Using the same CR protocol as in experiment 1 , we previously found increased insulin sensitivity in the epitrochlearis concomitant with reduced hexosamine levels in the plantaris muscle (Gazdag et al. 2000).

The endproducts of the HBP are UDP- $N$-acetylsugars which act as substrates for various transferases, including OGT. OGT activity is believed to be principally regulated by cellular hexosamine concentrations (Kreppel \& Hart 1999), although it is also susceptible to post-translational modifications which may alter its activity (Kreppel et al. 1997). Increasing the flux through the HBP results in increased levels of UDPsugar substrates and ultimately O-GlcNAcylation of 
(a)

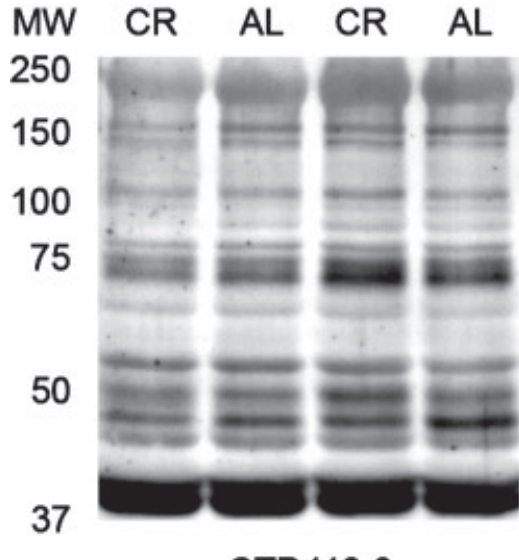

CTD110.6

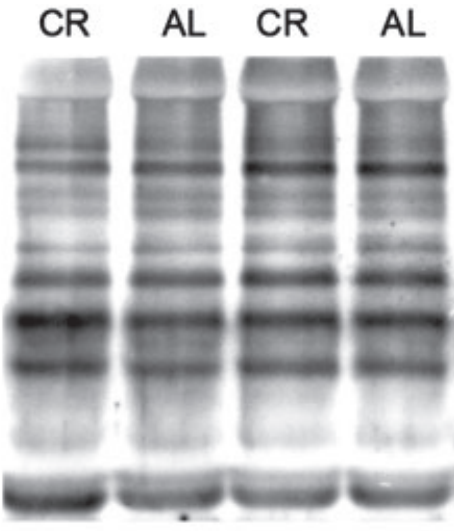

RL-2

(b)

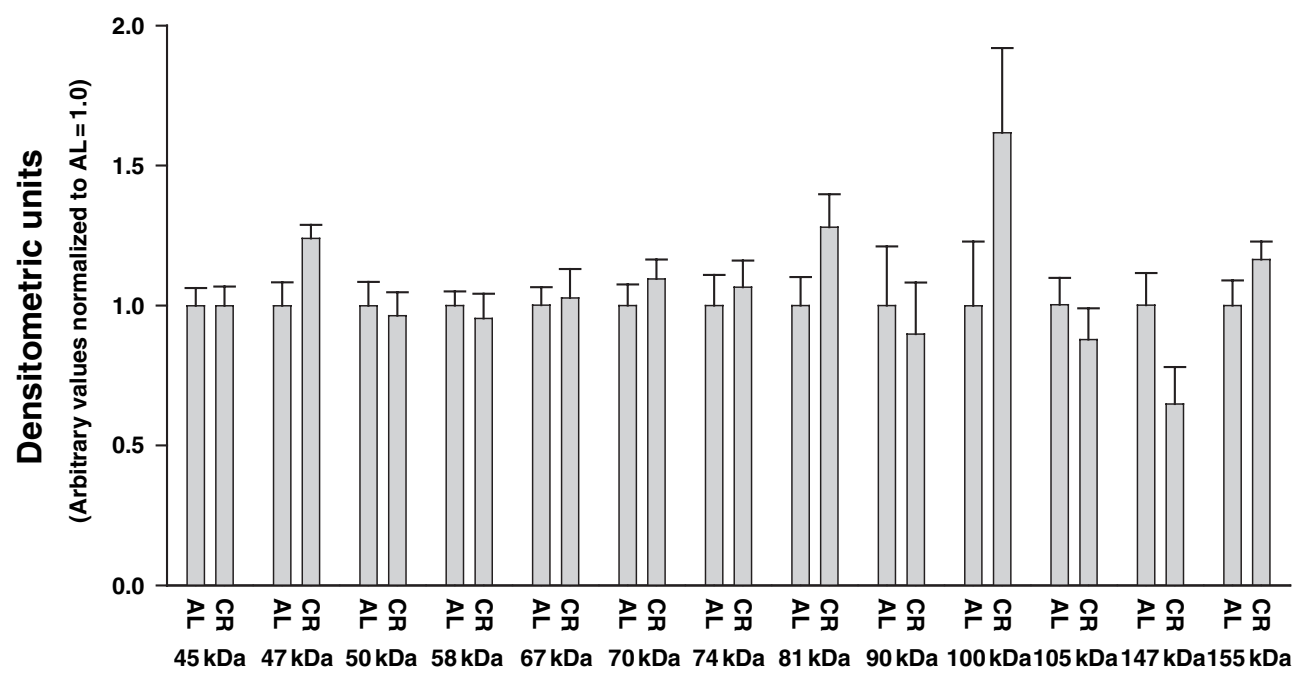

CTD110.6

(c)

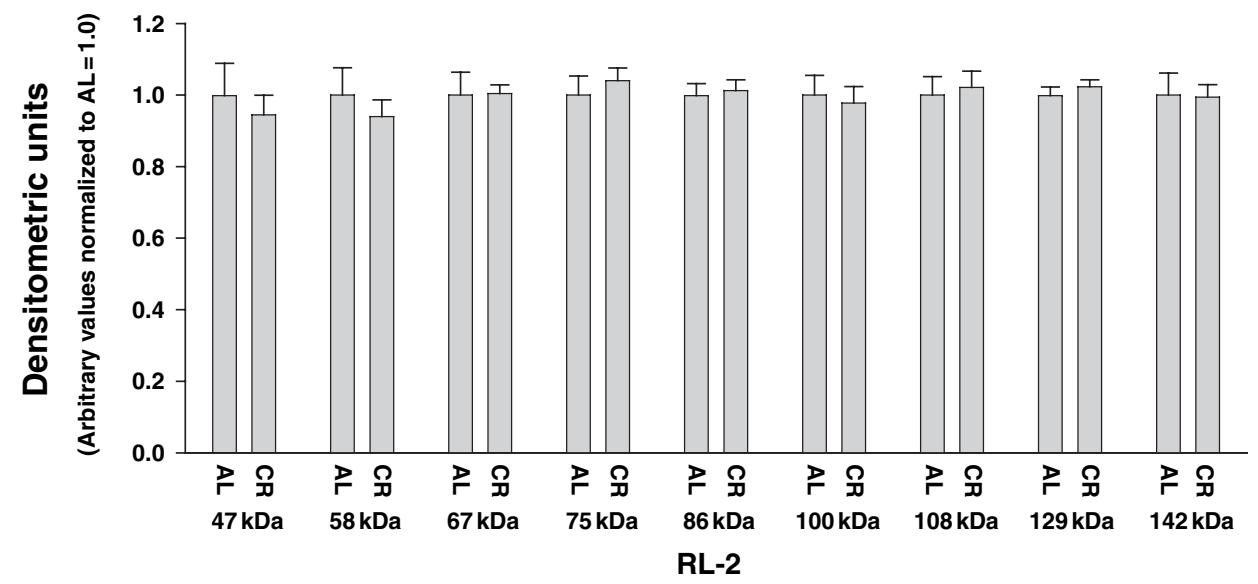

Figure I O-linked glycosylation of skeletal muscle proteins from 20 day CR and AL rats. (a) Homogenates were subjected to $8 \%$ SDS-PAGE. Protein blots were probed with anti-O-GlcNAc (CTD110.6 and RL2) and visualized following ECL. Relative molecular weight standards are denoted. Protein bands were quantitated by densitometry and values from CR-treated animals are expressed relative to the mean value for the corresponding protein band in muscles from AL rats (mean $\pm \mathrm{SE} ; n=7$ for $\mathrm{AL}, n=9$ for CR) for (b) CTD110.6, and (c) RL2. 
(a)

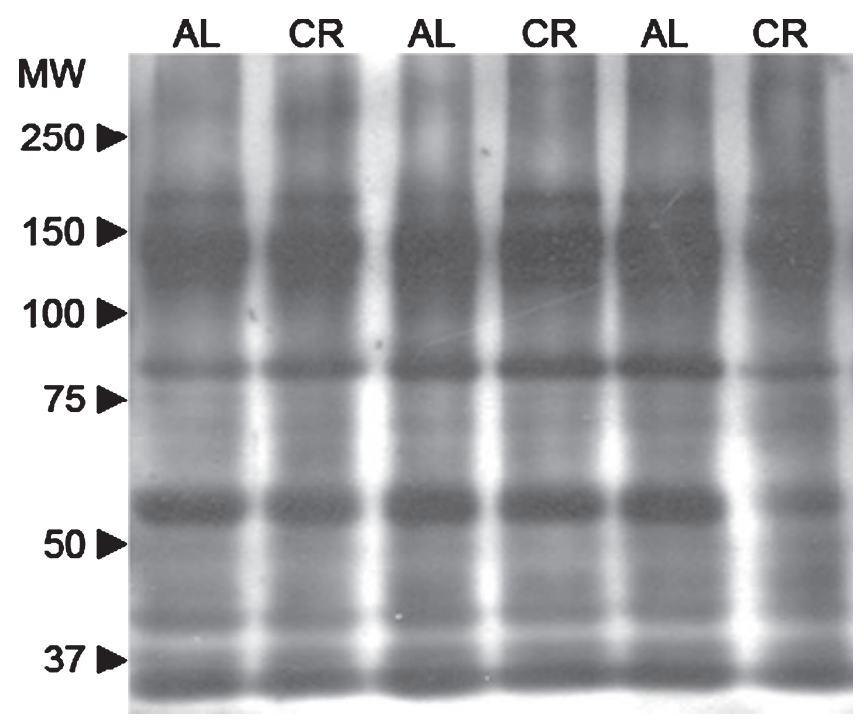

\section{(b)}

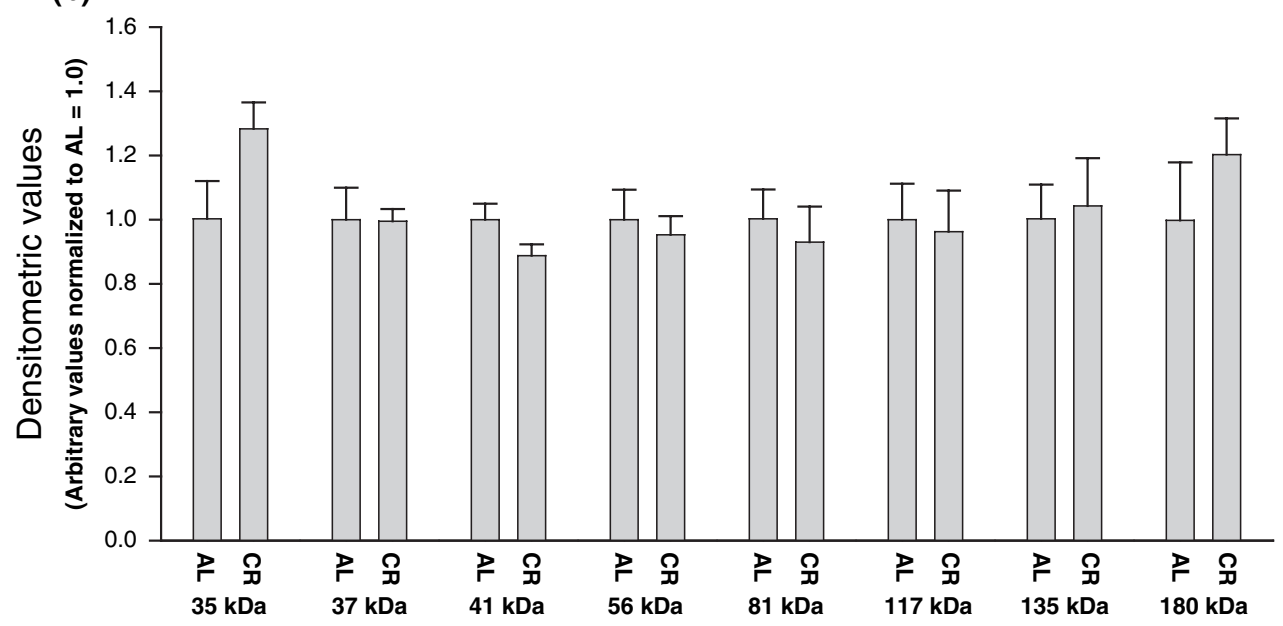

Figure 2 O-linked glycosylation of liver proteins from 20 day CR and AL rats. (a) Homogenates were subjected to 8\% SDS-PAGE. Protein blots were probed with CTD110.6 and visualized following ECL. Relative molecular weight standards are denoted. (b) Protein bands were quantitated by densitometry and values from CR-treated animals are expressed relative to the mean value for the corresponding protein band in muscles from $\mathrm{AL}$ rats (mean $\pm \mathrm{SE}$; $n=8$ for $\mathrm{AL}, n=8$ for $\mathrm{CR}$ ).

cellular proteins (Vosseller et al. 2002, Walgren et al. 2003).

In this context, the primary aim of this study was to examine whether the previously described CR-induced decrease in cellular hexosamines (Gazdag et al. 2000) was accompanied by an alteration in the protein $\mathrm{O}$ GlcNAcylation status in rat skeletal muscle.

We used two antibodies, CTD110.6 and RL2, which have been widely employed to detect O-linked glycosylation in cells and tissues (Patti et al. 1999, Vosseller et al. 2002, Walgren et al. 2003, Arias et al. 2004). Specifically, CTD110.6, which was generated against a synthetic glycopeptide with $\beta$-D-N-acetylglucosamine on an internal serine residue, recognizes O-GlcNAc with a beta-O-glycosidic linkage on both serine and threonine. In contrast, RL2 was generated against several O-GlcNAcylated proteins derived from the nuclear pore complex-lamina fraction of rat liver nuclear envelopes. Using these two antibodies, we were able to detect multiple protein bands. Several of the protein bands in skeletal muscle lysates were immunoreactive with both of the antibodies, suggesting the two antibodies may have recognized some of the same proteins. However, we were unable to detect differences in protein $\mathrm{O}-\mathrm{GlcNAcylation}$ between skeletal muscles from CR compared with AL rats using either antibody. We also found no effect of CR on levels of O-GlcNAcylated proteins in liver. 
(a)

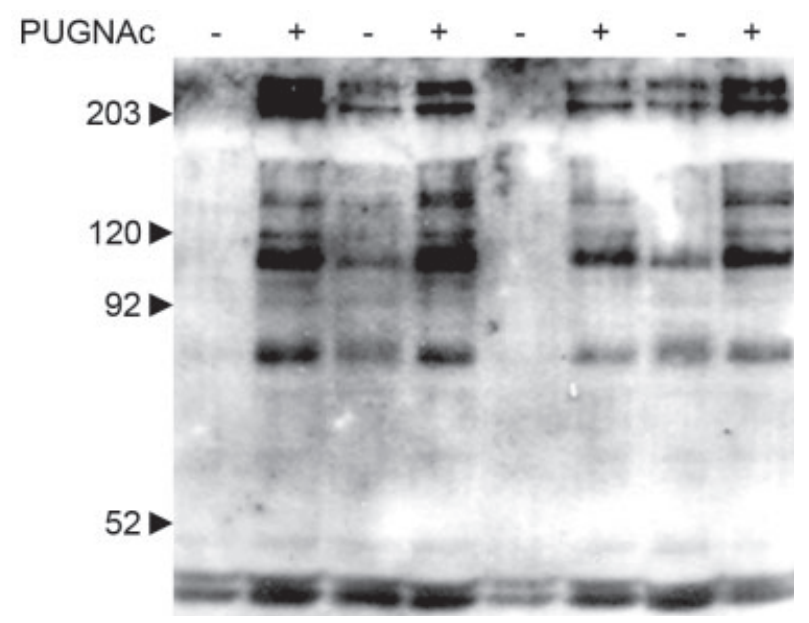

\section{(b)}

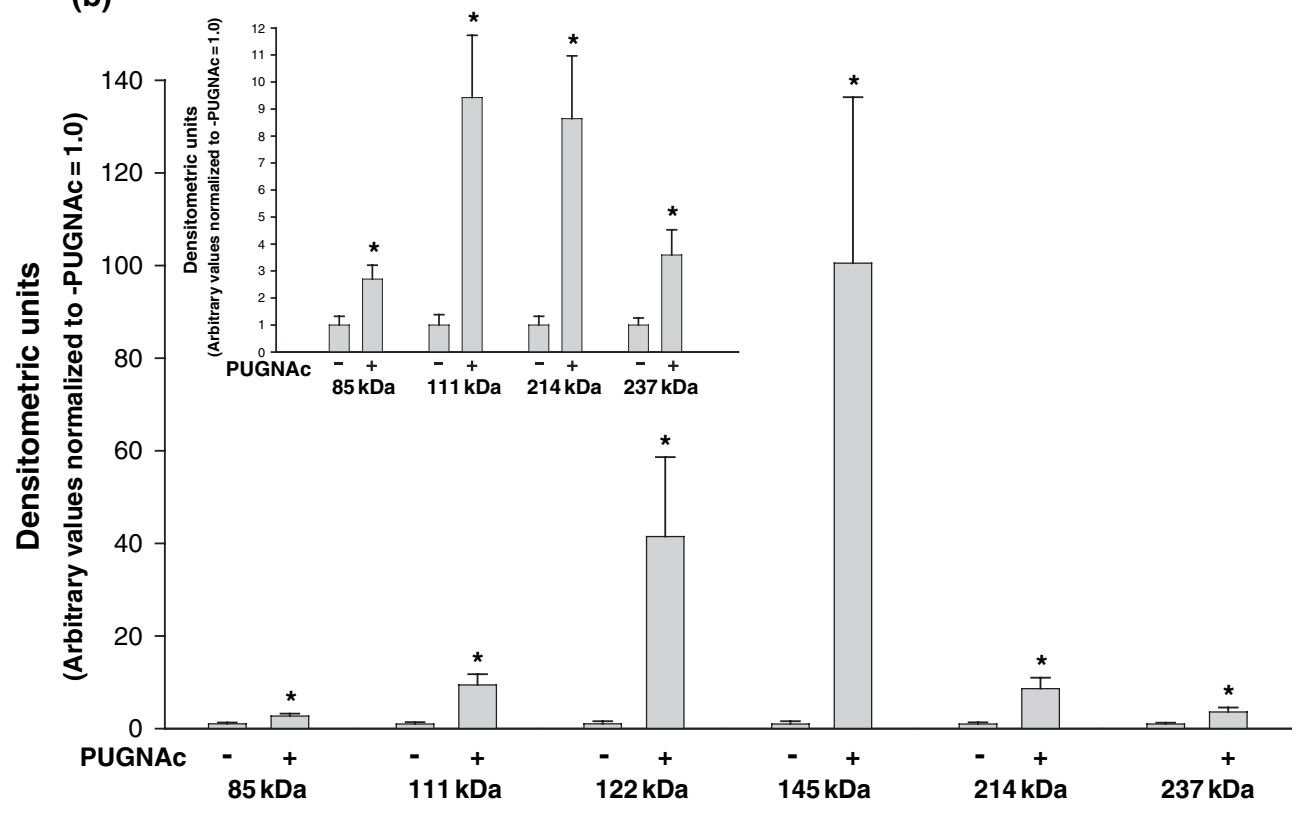

Figure 3 O-linked glycosylation of muscle proteins following $8.5 \mathrm{~h}$ incubation of paired skeletal muscles with or without $100 \mu \mathrm{M}$ PUGNAc. (a) Muscle homogenates were subjected to 8\% SDS-PAGE. Protein blots were probed with CTD110.6 and visualized following ECL. Relative molecular weight standards are denoted. (b) Protein bands were quantitated by densitometry and values for PUGNAc-treated samples are expressed relative to the mean value for the corresponding protein band in muscles incubated without PUGNAc (mean $\pm \mathrm{SE} ; n=6$ per group). Inset displays densitometric values for several protein bands using a different $y$ axis scale for clarity. *Significant difference for paired muscles with PUGNAc vs. without PUGNAc $(P<0.05)$.

Based on the mechanism we originally hypothesized might lead to a CR-related effect on protein O-GlcNAcylation, i.e. as the result of CR-induced reduction in UDP-GlcNAc, we would have predicted a general decline in O-GlcNAc-modified proteins. However, the current results argue against a robust, global effect of $\mathrm{CR}$ on protein O-GlcNAcylation in skeletal muscle. There are several possible interpretations for the lack of any detectable CR-induced change in protein O-GlcNAcylation, including: (1) brief CR did not affect protein O-GlcNAcylation in skeletal muscle and liver, (2) CR affected O-GlcNAcylation of proteins with low abundance and, therefore, below the sensitivity of our assays; (3) CR affected proteins with $\mathrm{O}$-GlcNAc motifs that are not recognized by the antibodies used; and/or (4) CR alters the O-GlcNAcylation of non-protein molecules (e.g. glycolipids). Other methods for detection of O-GlcNAcylation that do not rely on these antibodies (Roquemore et al. 1994) may be useful for subsequent 


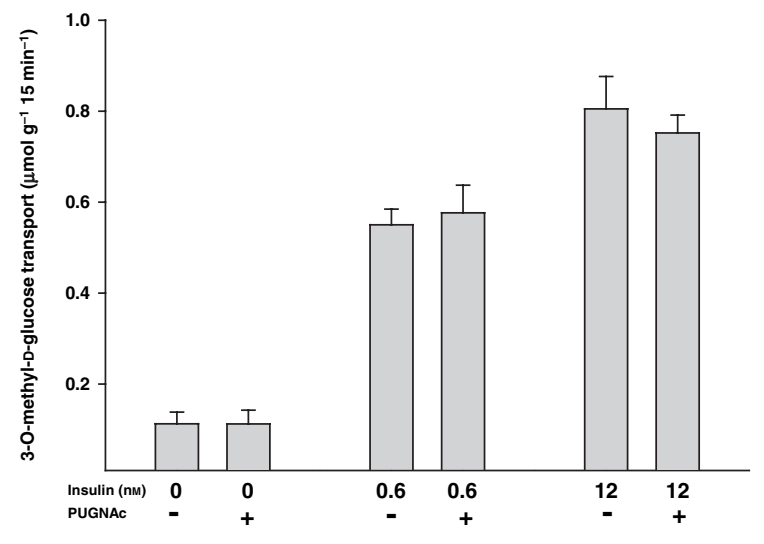

Figure 4 Rate of 3-MG transport in paired muscles after $8.5 \mathrm{~h}$ incubation in the presence or absence of $100 \mu \mathrm{M}$ PUGNAc. During the final $45 \mathrm{~min}$ of incubation, muscles were exposed to $0,0.6$ or $12 \mathrm{~nm}$ insulin. Data are mean \pm SE $(n=6$ per group).

research to distinguish among these possible explanations.

Recent studies have demonstrated that insulin resistance and increased protein O-GlycNAcylation can be induced by prolonged $(19 \mathrm{~h})$ incubation of skeletal muscle (Arias et al. 2004) and 3T3-L1 adipocytes (Vosseller et al. 2002) with PUGNAc, a potent inhibitor of O-GlcNAcase. In the current study, however, although protein O-GlcNAcylation in skeletal muscle was markedly increased by incubation with PUGNAc for $8.5 \mathrm{~h}$, this treatment did not alter basal or insulinstimulated glucose transport. Taken together with our previous results (Arias et al. 2004), these findings have important implications, because they indicate that a substantial increased in protein O-GlcNAcylation can precede PUGNAc-induced insulin resistance in skeletal muscle. The explanation for the delay between increased protein O-GlcNAcylation and induction of insulin resistance is unknown. Perhaps prolonged incubation with PUGNAc is required to achieve a sufficient level of O-GlcNAcylation of the specific proteins that lead to insulin resistance. Alternatively, prolonged PUGNAc exposure may induce insulin resistance indirectly through a relatively slow process, e.g. altered gene expression and protein abundance. Finally, although we believe this to be unlikely, it remains possible that PUGNAc-induced insulin resistance was unrelated to PUGNAc's well-established effect on O-GlyNAcylation of proteins. Further experiments will be needed to evaluate the potential importance of these suggested explanations.

In conclusion, we were unable to detect differences between $\mathrm{CR}$ and $\mathrm{AL}$ tissues (skeletal muscle or liver) for O-GlcNAcylation of proteins, although the UDPHexNAc levels in rat skeletal muscle are significantly lower for CR compared with AL rats (Gazdag et al. 2000). Secondly, we found that the induction of O-GlcNAcylation in skeletal muscle by exposure to PUGNAc, a potent inhibitor of O-GlcNAcase, precedes PUGNAc's effects on insulin sensitivity. Using an in vivo experimental model (CR) that leads to increased insulin sensitivity in skeletal muscle (Davidson et al. 2002), and an in vitro model (PUGNAc incubation) that leads to insulin resistance in skeletal muscle (Arias et al. 2004), we have dissociated the effects on insulin action from immunologically detected changes in protein O-GlcNAcylation. These findings argue that the effect of brief CR on insulin sensitivity is unlikely to be the direct result of a marked, global change in muscle levels of O-GlcNAcylated proteins.

This research was supported by National Institutes of Health Grant AG-10026 (GDC). We are grateful for the technical assistance from Junghoon Kim and Robert T. Davidson, PhD.

\section{References}

Arias, E.B., Kim, J. \& Cartee, G.D. 2004. Prolonged incubation in PUGNAc results in increased protein O-linked glycosylation and insulin resistance in rat skeletal muscle. Diabetes 53, 921-930.

Cartee, G.D. \& Dean, D.J. 1994. Glucose-transport with brief dietary restriction - heterogenous responses in muscles. Am J Physiol Endocrinol Metab 266, E946-E952.

Davidson, R.T., Arias, E.B. \& Cartee, G.D. 2002. Calorie restriction increases muscle insulin action but not IRS-1-, IRS-2-, or phosphotyrosine-PI 3-kinase. Am J Physiol Endocrinol Metab 282, E270-E276.

Dean, D.J. \& Cartee, G.D. 1996. Brief dietary restriction increases skeletal muscle glucose transport in old Fischer 344 rats. J Gerontol 51, B208-B213.

Dean, D.J. \& Cartee, G.D. 2000. Calorie restriction increases insulin-stimulated tyrosine phosphorylation of insulin receptor and insulin receptor substrate-1 in rat skeletal muscle. Acta Physiol Scand 169, 133-139.

Dean, D.J., Brozinick, J.T., Cushman, S.W. \& Cartee, G.D. 1998. Calorie restriction increases cell surface GLUT-4 in insulin-stimulated skeletal muscle. Am J Physiol Endocrinol Metab 38, E957-E964.

Gazdag, A.C., Tucker, M.Z., Turcotte, L.P., Dean, D.J. \& Cartee, G.D. 1998. Effect of extracellular palmitate on 2-deoxy-D-glucose uptake in muscle from ad libitum fed and calorie restricted rats. Biochem Biophys Res Commun 252, 733-737.

Gazdag, A.C., Dumke, C.L., Kahn, C.R. \& Cartee, G.D. 1999. Calorie restriction increases insulin-stimulated glucose transport in skeletal muscle from IRS-1 knockout mice. Diabetes 48, 1930-1936.

Gazdag, A.C., Wetter, T.J., Davidson, R.T. et al. 2000. Lower calorie intake enhances muscle insulin action and reduces hexosamine levels. Am J Physiol Regul Integr Comp Physiol 278, R504-R512. 
Hart, G.W. 1997. Dynamic O-linked glycosylation of nuclear and cytoskeletal proteins. Ann Rev Biochem 66, 315-335.

Hebert, L.F. Jr., Daniels, M.C., Zhou, J. et al. 1996. Overexpression of glutamine:fructose-6-phosphate amidotransferase in transgenic mice leads to insulin resistance. J Clin Invest 98, 930-936.

Holloszy, J.O., Chen, M., Cartee, G.D. \& Young, J.C. 1991. Skeletal muscle atrophy in old rats - Differential changes in the 3 fiber types. Mech Ageing Dev 60, 199-213.

Ivy, J.L., Young, J.C., Craig, B.W., Kohrt, W.M. \& Holloszy, J.O. 1991. Aging, exercise, and food restriction - effects on skeletal muscle glucose uptake. Mech Ageing Dev 61, 123133.

Kreppel, L.K. \& Hart, G.W. 1999. Regulation of a cytosolic and nuclear O-GlcNAc transferase. Role of the tetratricopeptide repeats. J Biol Chem 274, 32015-32022.

Kreppel, L.K., Blomberg, M.A. \& Hart, G.W. 1997. Dynamic glycosylation of nuclear and cytosolic proteins: cloning and characterization of a unique O-GlcNAc transferase with multiple tetratricopeptide repeats. J Biol Chem 272, 93089315.

Marshall, S., Bacote, V. \& Traxinger, R.R. 1991. Discovery of a metabolic pathway mediating glucose-induced desensitization of the glucose transport system. Role of hexosamine biosynthesis in the induction of insulin resistance. $J$ Biol Chem 266, 4706-4712.

McCurdy, C.E., Davidson, R.T. \& Cartee, G.D. 2003. Brief calorie restriction increases Akt2 phosphorylation in insulinstimulated rat skeletal muscle. Am J Physiol Endocrinol Metab 285, E693-E700.

Patti, M.E., Virkamaki, A., Landaker, E.J., Kahn, C.R. \& YkiJarvinen, H. 1999. Activation of the hexosamine pathway by glucosamine in vivo induces insulin resistance of early postreceptor insulin signaling events in skeletal muscle. Diabetes 48, 1562-1571.

Reaven, E.P., Wright, D., Mondon, C.E. et al. 1983. Effect of age and diet on insulin secretion and insulin action in the rat. Diabetes 32, 175-180.

Roquemore, E.P., Chou, T.Y. \& Hart, G.W. 1994. Detection of O-linked $\mathrm{N}$-acetylglucosamine (O-GlcNAc) on cytoplasmic and nuclear proteins. Meth Enzymol 230, 443-460.

Rossetti, L., Giaccari, A. \& DeFronzo, R.A. 1990. Glucose toxicity. Diabetes Care 13, 610-630.

Smith, P.K., Krohn, R.I., Hermanson, G.T. et al. 1985. Measurement of protein using bicinchoninic acid. Anal Biochem 150, 76-85.

Vosseller, K., Wells, L., Lane, M.D. \& Hart, G.W. 2002. Elevated nucleocytoplasmic glycosylation by O-GlcNAc results in insulin resistance associated with defects in Akt activation in 3T3-L1 adipocytes. Proc Natl Acad Sci USA 99, 5313-5318.

Walgren, J.L., Vincent, T.S., Schey, K.L. \& Buse, M.G. 2003. High glucose and insulin promote $\mathrm{O}-\mathrm{GlcNAc}$ modification of proteins, including alpha-tubulin. Am J Physiol Endocrinol Metab 284, E424-E434.

Wallberg-Henriksson, H. 1987. Glucose transport into skeletal muscle. Influence of contractile activity, insulin, catecholamines and diabetes mellitus. Acta Physiol Scand Suppl 564, $1-80$.

Wells, L., Vosseller, K. \& Hart, G.W. 2003. A role for $\mathrm{N}$-acetylglucosamine as a nutrient sensor and mediator of insulin resistance. Cell Mol Life Sci 60, 222-228.

Yki-Järvinen, H., Virkamaki, A., Daniels, M.C., McClain, D.A. \& Gottschalk, W.K. 1998. Insulin and glucosamine infusions increase $\mathrm{O}$-linked $\mathrm{N}$-acetyl-glucosamine in skeletal muscle proteins in vivo. Metab Clin Exp 47, 449-455. 